La tensión entre el derecho al desarrollo y el derecho a la libre determinación de los pueblos: un recorrido histórico-analítico La llegada a la teoría política de Boaventura de Sousa Santos

The tension between the right to development and the right to selfdetermination of peoples: a historical-analytical review. The arrival of Boaventura de Sousa Santos' to the political theory

Autor: Rodrigo Merayo Fernández

DOI: http://doi.org/10.25058/1794600X.1790 


\title{
LA TENSIÓN ENTRE EL DERECHO AL DESARROLLO Y EL DERECHO A LA LIBRE DETERMINACIÓN DE LOS PUEBLOS: UN RECORRIDO HISTÓRICO-ANALÍTICO LA LLEGADA A LA TEORÍA POLÍTICA DE BOAVENTURA DE SOUSA SANTOS*
}

\author{
The tension between the right to development and the right to \\ selfdetermination of peoples: a historical-analytical review. The \\ arrival of Boaventura de Sousa Santos' to the political theory \\ A tensão entre o direito ao desenvolvimento e o direito à \\ autodeterminação dos povos: um percurso histórico-analítico. \\ A chegada de Boaventura de Sousa Santos à teoria política
}

Rodrigo Merayo Fernández ${ }^{\mathrm{a}}$

rmerayo@ucm.es

Fecha de recepción: 16 de marzo de 2020 Fecha de revisión: 21 de marzo de 2020

Fecha de aceptación: 27 de abril de 2020

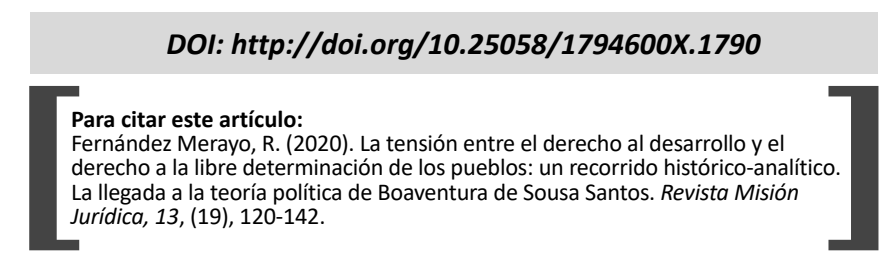

\section{RESUMEN}

La tensión entre el derecho al desarrollo frente al derecho a la libre determinación de los pueblos, es uno de los choques político-jurídicos más fechacientes y determinantes en los tiempos que corren, más aún en el contexto de globalización actual.

Este artículo de reflexión ha intentado mostrar cuál ha sido (desde un punto de vista analítico), y cómo ha influido (desde la pluma de tres autores notables y una escuela de pensamiento), la operatividad del modelo capitalista. El estudio recoge los primeros cuestionamientos, provenientes de América Latina, que dieron paso a la creación de la escuela estructuralista en los años cincuenta del pasado siglo, así como los escritos de Samir Amin, Jeffrey Sachs y la aportación del jurista y sociólogo Boaventura de Sousa Santos, que reflejan cómo ambos derechos se contraponen y, a su vez, son inseparables, más desde que fueran codificados bajo formas jurídicas a nivel internacional.

\footnotetext{
* Artículo de reflexión realizado como becario de colaboración en el Departamento de Historia, Teorías y Geografías Políticas de la Universidad Complutense de Madrid.

a. Graduado en Derecho por la Universidad de León, graduado en el máster de "Teoría Política y Cultura Democrática" por la Universidad Complutense de Madrid, graduado en el máster de "Acceso a la profesión de abogado" por la Universidad Nacional a Distancia (UNED). Ex-becario de colaboración en el Departamento de Historia, Teorías y Geografías Políticas de la Universidad Complutense de Madrid. Este trabajo se realizó en la labor de investigación que se me asignó cuando ejercí como becario de colaboración en la UCM.
} 
El asunto aquí tratado, que repercute básicamente sobre las zonas semiperiféricas y periféricas del mundo, acaba impicado al conjunto de la humanidad, precisando, en los tiempos actuales, de soluciones que intentar derretir el eje centro-periferia para caminar hacia un modelo mundial más justo en la redistribución. Las propuestas centradas en estrategias de desconexión como la de Amin acaban fracasando por la imposibilidad de generar un sentido común compartido, ahondando en la conformación de bloques antagónicas.

Problemas como el cambio climático, el medioambiente, la desigualdad, los derechos colectivos, etc.., precisan de responsabilidad y cooperación a escala local, nacional y, sobre todo, nacional. Debe de ser una respuesta de mutualidad y no de confrontación, eso sí, con respeto hacia los otros y respetando los tiempos de diálogo.

\section{PALABRAS CLAVE}

Desarrollo, autodeterminación, derechos humanos, Norte-Sur, periferia, semiperiferia, centro.

\section{ABSTRACT}

The tension between the right to development against the right to selfdetermination of peoples is one of the most powerful and decisive politicallegal clashes of our time, especially in the context of current globalization.

This research article has tried to reveal which has been (from an analytical perspective) and how it has influenced (from the pen of three remarkable authors and a school of thought) the operation of the capitalist world. This research gathers the first questions raised in Latin America, which led to the creation of the Structuralist School during fifties, and also the texts of Samir Amin, Jeffrey Sachs and the contribution of the jurist and sociologist Boaventura de Sousa Santos, that reflect how both rights are opposed and, at the same time, inseparable, even more since they were codified under legal forms internationally.

The issue discussed here, which basically affects the semi-peripheral and peripheral areas of the world ends up involving humanity as a whole, making necessary, in current times, solutions that try to melt the center-peripheria axis and move towards a world model more equal in redistribution. The proposals centered in disconnection strategies like Amin's, end up failing by the impossibility to generate a shared common sense and deepening the formation of antagonistic blocks.

\section{KEYWORD}

Development, selfdetermination, Human Rights, North-South, periphery, semi-periphery, center.

\section{RESUMO}

A tensão entre o direito ao desenvolvimento e o direito à autodeterminação dos povos é um dos embates político-jurídicos mais confiáveis e decisivos da atualidade, ainda mais no contexto da atual globalização.

Este artigo de reflexão procurou mostrar o que foi (do ponto de vista analítico) e como influenciou (da pena de três notáveis autores e de uma escola de pensamento) o funcionamento do modelo capitalista. 0 estudo reúne as primeiras questões, oriundas da América Latina, que deram lugar à criação da escola estruturalista nos anos 1950, bem como os escritos de Samir Amin, Jeffrey Sachs e a contribuição do jurista e sociólogo Boaventura de Sousa Santos, que refletem como os dois direitos se opõem e, por sua vez, são indissociáveis, principalmente porque foram codificados sob formas jurídicas em âmbito internacional.

0 assunto aqui discutido, que atinge basicamente as áreas semiperiféricas e periféricas do mundo, acaba envolvendo toda a humanidade, exigindo, nos tempos atuais, soluções que procurem fundir o eixo centro-periferia para caminhar em direção a um modelo de mundo mais justo. na redistribuição. Propostas voltadas para estratégias de desconexão, como a de Amin, acabam fracassando pela impossibilidade de gerar um senso comum compartilhado, mergulhando na formação de blocos antagônicos.

\section{PALAVRAS-CHAVES}

Desenvolvimento; autodeterminação; direitos humanos; Norte-Sul; periferia; semiperiferia; centro. 


\section{INTRODUCCIÓN}

El derecho al desarrollo y el derecho a la libre determinación de los pueblos es una de las tensiones más visibles en los tiempos de globalización actuales. Este trabajo pretende ser un recorrido de dicha tensión centrando su atención en los estudios y aportaciones de una escuela de pensamiento latinoamericana y tres intelectuales de notable categoría. Particularmente, dentro de estos tres últimos, la atención girará sobre la teoría política del pensador luso Boaventura de Sousa Santos.

Si bien el derecho al desarrollo comenzó siendo una reivindicación de los países sometidos a dominación colonial, durante el siglo XX, y de aquellos que habían alcanzado su independencia política, en el siglo XIX, acabó siendo conectado con un cierto tipo de desarrollo muy relacionado con las formas de producción capitalista. Como bien se verá más adelante en el apartado dedicado al economista norteamericano Jeffrey Sachs, el desarrollo moderno o contemporáneo se inició con la venida de la Revolución Industrial, la cual supondrá un antes y un después en el desarrollo del sistema capitalista.

La frontera entre el derecho al desarrollo y el derecho a la libre determinación de los pueblos es bastante difusa y estéril. Ambas son reivindicaciones provenientes de núcleos periféricos o semiperiféricos del mundo que tienen como principal objetivo la consecución del reconocimiento jurídico-real a nivel internacional de poder desarrollarse en las mismas condiciones que lo han hecho los países del Primer Mundo; como bien conjugan la Declaración sobre el Progreso y Desarrollo en lo Social (1969),la Carta Africana sobre los Derechos Humanos y de los pueblos (1981) y la Declaración sobre el Derecho al Desarrollo de Naciones Unidas (1986). Como se pondrá de manifiesto, esta reivindicación no solamente pretende quedarse en una formalidad jurídica sino que desea materializarse en la práctica a través de la codificación del derecho al mismo.

En este sentido, al calor del derecho al desarrollo que brota, sobre todo, desde las posiciones de la Escuela Estructuralista latinoamericana con los estudios de Raúl Prébisch, nace a su vez lo que se conoce como la teoría de la dependencia, la cual cristalizará en intelectuales como Cardoso, Faletto y Samir Amin (este último como representante del pensamiento africano). Es en este momento donde el derecho a la libre determinación o autodeterminación, como se recoge en la Declaración Universal de Derechos Humanos de 1948, comienza a ser relevante como intentará ponerse de manifiesto en los puntos segundo y tercero de este trabajo.

Curiosamente, los tiempos de globalización neoliberal han empujado y empujan, por un lado, a que el derecho al desarrollo se siga planteando en términos de disputa eje Norte-Sur mundial, chocando frontalmente con el derecho de autodeterminación en numerosas ocasiones debido a que, habitualmente, no suelen ir de la mano en lo que a política internacional se refiere.

Frente a una propuesta de desconexión y unión regional periférica como la que teoriza Amin, las aportaciones de Santos y Sachs pretenden ser una solución más acorde a nivel mundial para el conjunto de seres humanos ${ }^{1}$. Por ello, podría pensarse a día de hoy (como hacen Santos o Sachs en mayor medida) que el derecho al desarrollo ya no es cosa de algunos países o de las regiones periféricas del mundo, sino que el sistema de producción basado en la acumulación desorbitada de beneficio, el número de personas que habitan el mundo, los cambios climáticos acaecidos con motivo de la contaminación y la generación de basura, las grandes superficies agrícolas y ganaderas, etc.., han colocado el problema en términos civilizacionales.

\section{LA ESCUELA ESTRUCTURALISTA LATINOAMERICANA}

El estructuralismo nace alrededor de los años cincuenta del pasado siglo para reivindicar la situación de América Latina dentro del sistema económico capitalista mundial. $\mathrm{Su}$ punto de partida es el estudio del sistema mundial en su conjunto, centrándose tanto en los problemas como en las soluciones estructurales a las que arrastra el mismo. Su función principal consiste

1. Conviene aclarar que los estudios y aportaciones de Samir Amin suponen una receta determinada para la formulación o consecución de un mundo alternativo que haga frente o plante cara al modelo neoliberal actual y que, si es posible, se expanda lo más lejos posible. Por ello, me gustaría presentar aquí a Amin más que como un regionalista que apuesta por la desconexión, como un globalista "particularizado" o un globalista con temores que frente a lo que él considera como un sistema defectuoso, propone la desconexión como mejor artefacto para cambiar el mundo a nivel global. 
en poner encima de la mesa la desigualdad de condiciones y funciones que venía realizando América Latina como jugador global.

Para ello, organismos como la CEPAL, la cual ha sido central en este quehacer, plantearon y plantean a día de hoy un derecho al desarrollo propio o autónomo para aquellas regiones que se han quedado más relegadas dentro del sistema mundial como consecuencia de la posición que ocupan como operadores económicos globales. De esta organización, como veremos, también crece una rama más radical que planteará una teoría de la dependencia dentro del eje centro-periferia. La corriente dependentista, como se señalará más adelante, amplía el estudio de las causas y consecuencias de las zonas del sur periférico ya que van más allá del debate economicista, poniendo el foco de atención en patrones sociales, culturales, etc.

\subsection{ANTECEDENTES HISTÓRICOS}

Esta escuela nace durante los años cincuenta del pasado siglo como respuesta a una situación económico-política patológica en el continente latinoamericano. Como bien sabemos, los países que integran este continente, consiguieron la independencia política durante el siglo XIX. En el plano económico, se les consideraba dentro del marco liberal ortodoxo, el cual, "señalaba que la especialización y apertura comercial de los países termina generando bienestar a la población y que cada país debería producir aquel producto en el cual tuviese una ventaja comparativa [...]" (Briceño, Quintero y Ruíz, 2013:4).

En este reparto de tareas, los países latinoamericanos se encargarían de la especialización en la producción de materias primas. Acorde con esta teoría liberal económica, la productividad a gran escala de aquel costo de oportunidad por producir un bien daría lugar a beneficios que solo se podrían conseguir dentro de la interacción comercial entre países (Briceño Ruíz; Quintero Rizzuto; Ruíz de Benítez, 2013:4). Durante el período bélico europeo y la crisis de 1929 , los países latinoamericanos se encontraron en una situación de vulnerabilidad que generó tensiones sociales importantes debido a que,

las economías latinoamericanas se encontraron con la necesidad de proveerse de todos aquellos insumos que los países desarrollados no estaban produciendo ya que la economía de aquellos se había reorientado hacia la guerra primero, y hacia la reconstrucción posteriormente (Lilloy, 2015:7).

Ante ello, comenzó en la región un pequeño proceso de industrialización que traería consigo la urbanización de las ciudades para hacer frente a este contexto, provocando el desplazamiento de muchos campesinos al centro urbano para emplearse como trabajadores asalariados. Es lo que se conoce comúnmente como "centralización" o "concentración" de capital humano ${ }^{2}$. Aún en esta situación de desarrollo doméstico, las relaciones comerciales internacionales colocaban a los países latinoamericanos en desventaja frente a los del centro por el rol que les tocaba jugar como consecuencia del injusto intercambio y la nula bajada de precios industriales que debería de haber sucedido, si atendemos a los patrones teóricos clásicos del liberalismo económico ${ }^{3}$.

Tras ello, en el contexto post-bélico nacen las ideas de la mano de Prebisch del estructuralismo con la publicación en 1949 del documento titulado: "El desarrollo económico de la América Latina y algunos de sus principales problemas". Con la publicación de este documento, se inició un sendero que dió vida a la corriente de pensamiento estructuralista y sus distintas vertientes.

\subsection{EL PENSAMIENTO ESTRUCTURALISTA}

Como se destacó en el apartado anterior, esta corriente tiene su punto de partida en el pensamiento del economista Raúl Prebisch y la publicación de su informe para la CEPAL aunque, más tarde, se le unieron otras figuras de

2. Un proceso similar ocurrión en mi país, España, durante los años finales del franquismo. La apertura económica del mismo como consecuencia de la colocación de los conocidos como tecnócratas consiguió que se iniciase un proceso de industrialización que movió a miles de personas de las zonas rurales a los núcleos urbanos, abandonando el campo y centrándose en conseguir mano de obra barata que permitiese crear una fuerte industria y desarrollarse económicamente como país. Este asunto, si se quiere más información, viene tratado de manera excelente en el libro: DEL MOLINO, S.: La España Vacía, Ed. Turner: $1^{a}$ ed, Madrid, 2016.

3. Ello es buena prueba de que tanto la política como la economía son escenarios o contextos contigentes, en los cuales no se puede preveer exactamente qué o cómo van a suceder las cosas. Defender la tesis contraria sería situarse en una posición irrealista y peligrosa, jugando con probalidades y no posibilidades. Por ello, secundo la posición de Boaventura de Sousa Santos cuando sostiene que a las sociedades complejas y a los ciudadanos que habitamos en ellas nos conviene más ampliar el presente y estrechar el futuro. 
reconocido prestigio como son: Celso Furtado, Aníbal Pinto, Octavio Rodríguez, José Antonio Ocampo, entre otros.

El pensamiento estructuralista supuso un antes y un después dentro de la intelectualidad latinoamericana, teniendo adeptos tanto dentro como fuera del territorio latinoamericano. Fue y es una pieza fundamental para poner sobre la mesa el camino o caminos que los pueblos latinoamericanos tienen derecho a surcar como pueblos libres que son dentro del ámbito del derecho internacional. La base de sus estudios, la cual partía de la tesis de que existía un mundo dividido en dos categorías o estructuras (centroperiferia), dejaba entrever un mundo desigual compuesto por un centro desarrollado frente a una periferia subdesarrollada (Lilloy, 2015).

Todas estas circunstancias hicieron que Prébisch se replantease la ortodoxia económica liberal allá por los años cuarenta del siglo pasado, cuando América Latina ocupaba una posición como productora y exportadora de materias primas en grandes proporciones, pero no se veía recompensada en la distribución de los beneficios del progreso técnico a escala mundial (Díez, 2013). Esta problemática se pone de manifiesto en las siguientes palabras del economista argentino:

Yo creía en todo aquello que los libros clásicos de los grandes centros me habían enseñado [...]. Creía que todos los problemas de desarrollo se resolvían por el libre juego de las fuerzas de la economía mundial [...].

para continuar diciendo que,

era tan grande la contradicción entre la realidad y la interpretación teórica elaborada en los grandes centros, que la interpretación no solo resultaba inoperante cuando se llevaba a la práctica, sino también contraproducente (Prebisch, 1963: 59).

Que América Latina ocupase esta posición no agradaba a los cepalinos ${ }^{4}$ pero, pese a esto, y es curioso este punto, tampoco era el núcleo central

4. Se denomina "cepalianos" a aquellos intelectuales, políticos o seguidores de las propuestas surgidas en el seno de la CEPAL, promotores y pertenecientes a la escuela estructuralista pero que se les denomina de esta manera para diferenciarlos de los integrantes de la corriente nacida también del estructuralismo, conocida con el nombre de dependentismo. de su crítica, más bien, lo que verdaderamente les preocupaba era que los países latinos no se habían visto beneficiados por la relación de precios desde los años setenta del siglo XIX, ni tampoco de los beneficios del progreso industrial, los cuales se habían concentrado únicamente en los productores de bienes industriales en contra de los cánones clásicos de la teoría económica del comercio internacional.

Esta teoría auguraba que la instauración del libre comercio beneficiaría a todos los países que participasen de la misma y evitaría la guerra. Lo primero, históricamente, se ha demostrado que no ha sido un reparto por igual de los beneficios entre todos los países operativos en el ámbito mundial ${ }^{5}$. Ello no es óbice para reconocer que la mejora ha sido sustancialmente notable y que en los tiempos más cercanos algunos países de Latinoamérica se han visto beneficiados como consecuencia de la interacción comercial, posibilitando que puedan ser corregidas desigualdades económicas y avanzando en la prosperidad. Con respecto al asunto de intentar frenar las guerras, es verídico que la cooperación económica internacional, presente desde la Paz de Westfalia, ha conseguido disminuir los conflictos bélicos impulsando la posibilidad de que los Estados lleguen a acuerdos en los que se vean beneficiados. Es un hecho indiscutible que la utilización de la lógica dialógica ha contribuido a lo largo de la historia a reducir o anular la violencia en beneficio del acuerdo $^{6}$. No se entiende en otro caso la llegada de la democracia, aunque sea en mínimos, a nuestras sociedades.

Este fenómeno (la teoría de la ventaja comparativa) daría paso a lo que denominarían deterioro de los términos de intercambio o intercambio desigual en el eje centro-periferia. Frente a esta injusticia en el intercambio comercial, los estructuralistas propusieron el

5. Díaz Colorado, parafraseando a Reyes Mate:2006, afirma: "el concepto de igualdad que promulgó la modernidad, y que ha fundamentado durante gran parte de la historia la concepción de justicia, es algo sospechoso ya que oculta tras de sí grandes desigualdades, que no se muestran ni se tienen en cuenta" (Díaz Colorado, 2012: 269).

6. Este asunto está presente en la teoría democrática habermasiana de manera fechaciente. El autor alemán se encarga de destacar que la violencia política ha conseguido ser anulada o desechada por medio del diálogo o de la comunicación siendo este hecho una constante si ponemos nuestro centro de atención en el avance democrático o en la teoría de los derechos humanos. 
desarrollo de la industrialización nacional como receta para iniciar un proceso modernizador.

El fomento del orden interno supondría sustituir o reducir la excesiva importación de bienes industriales, comenzando a crearse los propios nacionales. Se mantendría la producción de alimentos y la exportación de materias primas al centro para financiar el desarrollo industrial interno, junto a una reforma de carácter agrario, fiscal, atraer mano de obra del campo a ciudad, etc. En consecuencia,

este patrón de desarrollo de la periferia se denominó modelo exportador primario o desarrollo hacia afuera, y se entendía que la superación del subdesarrollo latinoamericano implicaba el reemplazo de este modelo por uno de crecimiento hacia adentro, cuyo núcleo debía ser la promoción de un proceso de industrialización con sustitución de importaciones (Briceño Ruíz; Quintero Rizzuto; Ruíz de Benítez, 2013:7).

Como se puede apreciar en la cita textual, los estructuralistas destacaban con su interpretación del sistema económico mundial que existían desigualdades entre los países de la periferia y los países del centro, sin embargo, en ningún momento se puede extraer de su razonamiento que rechazasen un proceso de modernización o desarrollo que les llevase a situarse en posiciones análogas a las de los mismos. Su objetivo, a fin de cuentas, era conseguir alcanzar un status económico y de bienestar social similar a la de los países del centro mundial. Ello, desde el punto de vista de la lógica y del bienestar ciudadano, es totalmente comprensible. Pensar en la posibilidad de colocarse en una posición en la que pudiesen tratar de tú a tú a un país europeo implicaba tener un poder económico consistente y fuerte. Lo cierto es que el asunto, si echamos la vista atrás, no parece dar pie a pensar que ello sea la solución a los problemas del desarrollo.

Si bien es cierto que la autodeterminación como país permite gestionar tus propios intereses, permitiendo desarrollarte de forma más autónoma dentro de un sistema capitalista mundial, no parece que seguir el ejemplo de los países del centro sea la solución. Más bien, en los últimos años, se ha podido comprobar con la llegada de gobiernos progresistas a las instituciones en todo el continente lationamericano dos cosas: por un lado, destacar que la posibilidad de efectuar políticas económicas alternativas dentro del propio sistema capitalista por parte de los países latinoamericanos parece poder conseguirse únicamente cuando se trabaja en la dirección de la unión regional. Por otro lado, la cuestión de la herencia colonial y la ineficacia institucional son problemas difíciles de superar pero no imposibles, haciendo repensar si existe la posibilidad de que dentro de un sistema capitalista global diseñado casi en su totalidad para la promoción de los países del espectro permita que países que históricamente han estado bajo el yugo de la dominación sean capaces de disputar la hegemonía mundial.

Tras este paréntesis, hay que destacar que los estructuralistas también tuvieron una preocupación con respecto a los problemas derivados de las estructuras de carácter interno pero centrando más su atención en los análisis economicistas. Como consecuencia de ello, nacerá alrededor de los años 60 la corriente dependentista marxista, más centrado en el funcionamiento de las estructuras internas de los países latinoamericanos pero sin olvidar la importancia de la economía. Esta corriente, en términos generales, combinará un análisis integrado del desarrollo usando la herramienta de la sociología.

\subsection{LA TEORÍA DE LA DEPENDENCIA O CORRIENTE DEPENDENTISTA}

Se puede ubicar, en los años 60, con la promulgación del texto "Dependencia y desarrollo en América Latina", de Fernando Henrique Cardoso y Enzo Faletto (1998). En este documento se centraba la atención en el proceso de industrialización interno que había iniciado América Latina tras el período bélico europeo, siguiendo un camino similar al de los países desarrollados para homologar sus niveles de desarrollo e intentar hacer frentes a los problemas de los países subdesarrollados. Todo ello se desvaneció cuando en los años 50 hubo un estancamiento de la economía regional, dando paso al nacimiento de esta corriente teórica por parte de diversos autores que intentarán dar respuesta al fracaso del intento de autosustentación (Lilloy, 2015: 22). Por ello autores como Cardoso y Faletto, 1977, centrarán sus esfuerzos en articular un compendio teóricopráctico que posea las siguientes características: 
un análisis integrado que otorgue elementos para dar respuesta en forma más amplia y matizada a los interrogantes generales sobre las posibilidades del desarrollo o estancamiento de los países latinoamericanos, y que responda a las preguntas decisivas sobre su sentido y sus condiciones políticas y sociales (1977:7).

Durante la década de los sesenta, la realidad demostró que el modelo de industrialización por sustitución planteado por el estructuralismo no trajo consigo todos los avances que se esperaban, sobre todo en el ámbito de la pobreza urbana. De nuevo, para achacar esta situación, los cepalinos intentaron dar respuesta fomentando una fase superior de la industrialización basada en la producción de bienes intermedios y de capital y la exportación de manufacturas, apostando también por la integración latinoamericana que daría paso a la creación de un mercado regional común ${ }^{7}$ (Díez, 2013: 13).

Como consecuencia de lo anterior, nació la teoría dependentista con raíz en el estructuralismo y cuyas posturas se asocian al marxismo crítico. Los dependentistas también tomaron como base teórica de explicación el eje centro-periferia, mostrando que la distinción entre sociedades tradicionales versus modernas es más amplia de lo que el estructuralismo planteaba. Lo novedoso de su aportación gira en torno a la inclusión de los grupos sociales y el uso del término "dependencia" en sus análisis, estableciendo que:

El objetivo de este ensayo es explicar los procesos económicos como procesos sociales [...], esquemáticamente se puede decir que el problema del control social de la producción y el consumo constituye el eje de un análisis sociológico del desarrollo orientado desde esa perspectiva (Cardoso y Faletto, 1977:11).

Desde allí se asentaran los cimientos para redefinir las categorías tradicionales del desarrollo, las cuales fueron categorizadas en subdesarrollo, periferia y dependencia. En todo momento, los dependentistas focalizaron la situación de subdesarrollo con la expansión del capitalismo comercial e industrial, poniendo

7. Solamente el Pacto Andino de 1969 recogería verdaderamente las propuestas estructuralistas de integración en casi su totalidad. énfasis que los países periféricos entraron a formar parte del modelo capitalista internacional cuando las reglas del mismo ya habían sido establecidas por los países del centro (Cardoso y Faletto, 1977). Por ello, es lógico que entendiesen que la categorización entre economías desarrolladas y subdesarrolladas fuese más allá que una simple diferencia de etapas, sino más bien una configuración de la estructura económica global basada en la producción y la distribución ( Lilloy, 2015). Toda esta concepción es sintetizada de una forma brillante mediante la siguiente reflexión:

la caracterización de subdesarrollo habla del estado o grado de diferenciación del sistema productivo sin acentuar las pautas de control de las decisiones de producción y consumo, mientras que las nociones de centro y periferia subrayan las funciones que cumplen las economías subdesarrolladas en el mercado mundial. En este sentido, la situación de dependencia en el análisis de desarrollo latinoamericano pone de manifiesto el modo en el que las economías nacionales se integran al mercado internacional, vinculando a los grupos sociales de cada país entre sí y con los grupos externos (Lilloy, 2015: 24-25).

Entonces, siguiendo las tesis dependentistas, no se podía plantear el subdesarrollo como condición para la evolución ya que este se generaba como consecuencia de la división internacional del trabajo y de la posición que acaba determinando la productividad en la estructura económica global.

Unido a lo anterior y como punto de interés que les distingue de los análisis del estructuralismo clásico, esta corriente defendía y defiende que la dependencia no solo se manifiesta en el ámbito externo comercial sino que también se hace operativo en el plano doméstico- nacional, manifestándose a través de las estructuras e instituciones de dominación en el plano ideológico, social y político. Siguiendo a dos Santos, y para terminar con el estudio de esta rama de conocimiento, sostenemos que:

la teoría de la dependencia procuró demostrar que la industrialización no traía las consecuencias esperadas por la visión desarrollista y nacional-democrática [...], pero trajo consigo un estilo científico 
latinoamericano autóctono [...], caracterizado por un enfoque interdisciplinario, dialéctico e histórico-estructural que enfatiza especialmente en el análisis de la totalidad y su relación con las partes (2002: 107-110).

En esta última reflexión, dos Santos nos muestra cómo el nacimiento de la Escuela Estructuralista Latinoamericana y su escisión dependentista ponen encima de la mesa, por vez primera, el cuestionamiento del sistema económico clásico mediante la constitución o conformación de grupos de intelectuales propios de Latinoamérica, intentando dar respuesta a problemas comunes, amplios, compartidos y relacionados con el derecho al desarrollo autónomo dentro del seno de la región latina y caribeña. Concretamente, como se ha querido reseñar, la teoría dependentista fue más allá e integró una visión que trascendía lo económico para situarse también en otras esferas de influencia como pueden ser la cultura o la posición social.

\section{EL PENSAMIENTO DE SAMIR AMIN: LA CUESTIÓN DE LA DESCONEXIÓN}

Este siguiente apartado del recorrido centrado en la tensión entre el derecho al desarrollo y el derecho a la libre determinación de los pueblos, se ha tomado la figura del reputado economista egipcio Samir Amin. Proveniente de una rama heterodoxa del marxismo, Amin tuvo continuidades con respecto a las teorías estructuralistas pero sintonizó de manera más fehaciente con las corrientes dependentistas. Ha sido catalogado dentro de aquellos intelectuales no occidentales que desarrollaron su obra teniendo como foco de preocupación la situación de los países no pertenecientes a la órbita occidental.

Antes de llegar a la propuesta teóricopolítica innovadora, atrevida e interesante de Amin (la desconexión), la investigación de servirá de algunas franjas temporales de la vasta periodización del sistema político mundial que realizó el pensador egipcio. Más concretamente, se centrará desde finales del siglo XX hasta nuestros días.

Antes de desarrollarla, conviene apuntar que para Amin era imposible llevar a cabo una periodización del sistema capitalista sin hacer referencia al concepto de "polarización"8 que genera el mismo. Conviene aclarar que esta periodización de la historia forma parte de una idea del autor, la cual puede quedar sometida a discusión debido a la difícil labor que supone la fragmentación de la historia para la articulación de teorías, reflexiones o pensamientos.

La primera fase comprende desde 1945 hasta 1990. La Segunda Guerra Mundial supuso un trastocamiento del sistema anterior imperante por el advenimiento del sistema de bienestar en el centro, el debilitamiento económico de la URSS, la anexión de los países de Europa Central al capitalismo mundial impulsado por EEUU, los procesos de descolonización e independencia de las colonias en el Tercer Mundo bajo movimientos de liberación nacional o nacionalismos populistas y el proceso de industrialización periférico autónomo que acarrearon los mismos.

Lo determinante de esta etapa fue la conformación de un sistema mundializado que no se basaba en la subordinación plena al capital sino que se introdujeron elementos de consenso que giraban en torno a la idea de pacto capitaltrabajo o empleador-trabajador, en el centro, $\mathrm{y}$ que, en la periferia, se presentaron como lógicas basadas en el "rattrapage". Es decir, nos encontrábamos ante un escenario temporal en el que se plantearon lógicas o acciones antisistémicas de corte emancipador que, más adelante, quedaron disueltas en contradicciones debido a la reconfiguración de fuerzas del capital. Esta situación comenzó bajo el modelo de Estado keynesiano europeo a partir de finales de los años setenta, consolidándose finalmente bajo la caída del Muro de Berlín en 1989 y de la URSS en 1991.

Paralelamente a estos tres fenómenos, resaltaba el propio Amin que, lo curioso del asunto, fue cómo en un contexto posbélico, también se fue desarrollando una hegemonía de

8. Cuando habla de polarización, se refiere a la generación de desigualdades que se producen como consecuencia de la dinámica de funcionamiento del sistema capitalista, dando paso a la conformación de zonas centro y zonas periféricas.

9. "Con este término se refiere a la posibilidad de recuperar de reatrapar, el atraso respecto a cierto fenómeno o proceso en curso. En este caso, el término hace referencia a la imposibilidad de los países periféricos de alcanzar niveles de desarrollo similares a los de los países centrales. Esto se debe a que, según explica el autor, a diferencia de lo que sucedía en la Antigüedad, la lógica actual de la mundialización no otorga estas oportunidades a los países periféricos". Citado en: AMIN, S.: Capitalismo, Imperalismo, Mundialización, Ed. CLACSO, 2001. 
EEUU que se concretó en lo que él llamó la "Triada Imperalista" o "imperalismo colectivo"10.

Esta nueva forma de imperalismo se encontraba sustentada por un instrumento que cobró especial importancia en la explicación del egipcio y que le puso el nombre de: "los cinco monopolios $^{\prime \prime 11}$ (Corátolo, 2011:7-26). Sin los cinco monopolios era imposible que pudiese existir la triada imperialista, por lo que ambos acababan encontrándose en una relación de dependencia el uno del otro. Para ser más preciso y no dar lugar a dudas, en palabras del propio autor:

la Segunda Guerra Mundial modificó las condiciones que guiaban la expansión capitalista polarizante de este siglo y medio de historia moderna. La derrota del fascismo modificaba profundamente las relaciones sociales de fuerza a favor de las clases obreras, que adquirieron en los centros posiciones que nunca habían conocido con anterioridad en el capitalismo; a favor de los pueblos de las periferias, cuyos movimientos de liberación reconquistaron la independencia política de sus naciones: a favor del modelo soviético del socialismo realmente existente, que aparecía como la forma más eficaz del proyecto de desconexión y de rattrapage. Al mismo tiempo, la consolidación de la predominancia norteamericana sobre todos los otros centros capitalistas modificaba las condiciones de la competencia inter-imperalista (Amin, 2001:19).

La segunda y última etapa que aquí interesaba para esta labor comenzó a gestarse desde finales de los años setenta y llega hasta nuestros días, naciendo con el deterioro de los tres sucesos mencionados anteriormente (modelo soviético,

10. Con este término, Amin hace referencia a la conjunción de potencias o, en este contexto, más bien países (pese a que EEUU sí esté considerada como potencia dominante) occidentales que van a uniformar posiciones y se van a adherir al proyecto universalista económico que propone los Estados Unidos. Serían los siguientes países: Canadá, Europa Occidental, Japón y los EEUU.

11. Con este concepto, Samin nos sitúa la potencialidad de EEUU en la ostentación de ciertas áreas o sectores en los que se ha asentado como ente predominante, lo cual, le ha llevado a un cuadro de preeminencia con respecto a los demás actores. Las esferas de las que habla Amin serían las siguientes: monopolio tecnológico, control de los mercados financieros, acceso monopolista a los recursos naturales del planeta, monopolio de los medios de comunicación y monopolio de las armas de destrucción masiva. las conquistas periféricas y el Estado de Bienestar). Comenzaron a sentarse las bases de lo que conocemos con el nombre de neoliberalismo ${ }^{12}$ , el cual, intrínsecamente, queda atravesado por una clara vocación de universalidad.

Con ello, podemos decir que la teoría o el discurso de la mundialización, que nunca ha dejado de presentarse por parte de Amin como sinónimo de imperalismo, recuperó su faceta más "radical" en términos de desigualdad.

La erosión de los tres acontecimientos de la fase anterior generaron la posibilidad de plantear una nueva forma de imperialismo, basado en dicha lógica neoliberal, acentuando las desigualdades entre centro-periferia por una serie de sucesos: el desgaste del Estado-nación ${ }^{13}$ , la inversión del eje nacional/mundial a uno mundial/nacional donde se le asignaba un papel determinante a las empresas transnacionales, las instituciones internacionales como transmisores a nivel mundial de esta reactualización del liberalismo imponiendo programas de "ajuste estructural" frente al escenario societario anterior, el papel hegemónico de los EEUU apostando por un sistema capitalista financiarizado y la pérdida de la dimensión emancipadora en las periferias que había sido impulsada por los movimientos nacional-populistas.

Todo esta lógica de vuelta a la unilateralidad del capital suponía para el pensamiento del egipcio, de nuevo, apostar por un bloque antiobrero o anti-popular. El instrumento perfecto usado por parte de estas élites para generar esta nueva polaridad se materializó a través del

12. Para ser fiel a la labor de reflexión que este artículo pretende ser, conviene precisar qué entiendo por neoliberalismo. Por ello, tomo como punto de partida el detallado estudio del pensador británico David Harvey. El mismo se centra en explicar que el neoliberalismo consiste en un proyecto político desplegado por las clases capitalistas corporativas iniciado a finales de los años setenta. Más centrado en lo económico que en lo político, el neoliberalismo se presenta como un sistema potenciador de la competitividad desmesurada, de la individualidad y de una fuerte cultura del consumo. Era presentado como un proyecto contrarrevolucionario frente al Estado de bienestar keynesiano. Para más información sobre este asunto, véase: HARVEY, D.: Breve Historia del Neoliberalismo, Ed. Akal; Madrid, 2007.

13. Aquí, más bien, me atrevería a decir que más que un desgaste del Estado-nación en términos políticos, Amin plantea el mismo dentro del discurso. Es decir, muestra la paradoja liberal o neoliberal, que ya Foucault muestra en sus estudios sobre la biopolítica, acerca de la regulación como mecanismo de la propia desregulación. Entonces, el asunto del Estado mínimo o superado por lo global quedaría cuestionado o al menos sometido a debate. 
concepto de "los cinco monopolios". Ello era lo que permitía someter de nuevo a la periferia a las exigencias del centro a través de las instituciones internacionales (FMI, BC, OMC...) y, más concretamente, con la concesión de créditos internacionales dirigidos al "desarrollo".

Para Amin este discurso era una completa falsedad ya que, dentro del sistema capitalista, veía como imposible hablar de un desarrollo propio por su marcado carácter ideológico, desigual e imperalista. De ahí que lo concibiese como un producto que venía ya determinado por estándares occidentales definidos a priori y que, en buena parte había sido asumido en la periferia con expresiones como "países en vías de desarrollo". Esta forma en la que se entendía el desarrollo dentro del capital debía de abandonarse radicalmente (Corátolo, 2011:10).

Especial atención merece el papel que le otorgaba a las empresas transnacionales, debido a que las presentaba como motores de transformación del sistema de división global del trabajo en un sistema dividido, ahora, al interior de la firma.

Esto último, ponía encima de la mesa la tentaculización de lo transnacional alrededor de los cinco continentes con motivo de que el desarrollo de la periferia pasaba de ser autónomo a quedar reducido a la categoría de subcontratación.

Además, destacaba Amin (1992:177) que el concepto de "Tercer Mundo" ya no convenía presentarlo como una unidad homogénea sino que, más adecuadamente, debería de hablarse de dos grupos de países: un primer grupo integrado por aquellas regiones que formaban parte de un sistema competitivo manufacturado como Asia Oriental, América Latina, India y el Sudeste Asiático; en el otro grupo estaban aquellos países que no habían entrado ni en una era industrializadora, estando atrapadas en la exportación de materias primas. Estaría representado por el continente africano y convendría acuñarle, de forma más correcta a su entender, con el nombre de "Cuarto Mundo".

Este análisis estuvo un tiempo en entredicho como consecuencia del ascenso de los famosos países de los BRICS. Sobre todo, a día de hoy, con el papel de China, la cual, en términos netamente macro-económicos, podríamos considerarla como una potencia desarrollada. También sería interesante contraponer la mirada de Amin a la de autores como John Agnew ${ }^{14}$ (2005), al plantear que estamos en un período de hegemonía respecto a las reglas de juego económicas pero sin un claro hegemón, como planteaba el reputado economista egipcio con respecto EEUU. Finalmente, para terminar con el estudio de la teoría del intelectual africano formado en París, conviene tratar lo que ha pasado a erigirse como el núcleo central de su teoría económico-política: "la desconexión".

¿Qué implicaba la desconexión? o, más bien, ¿Qué era la desconexión? Pues bien, cuando Amin propuso este instrumento estaba pensando en una estrategia que hiciese frente a lo que él consideraba una situación de desarrollo desigual, monopolística e imperalista. El contexto en el que brotó como fruto de su pensamiento, en el cual los EEUU, Europa Central y Japón eran jugadores y árbitros, debía de ser contraatacado en forma de desobediencia hacia la mundialización existente. Para ser más preciso, "la desconexión supone subordinar las relaciones externas a la lógica del desarrollo interno y no al revés" (Corátolo, 2011:74). En esta reflexión está la raíz del asunto. Es aquí donde se conjugaba el derecho al desarrollo propio, con la consiguiente condición de que el mismo fuese un desarrollo de carácter libre, no sometido a interferencias o injerencias externas.

Suponía el abandono de las recetas de "ajuste estructural" para conformar un escenario de desarrollo propio impulsado por las clases populares y desobedientes. Amin no abandonó en ningún momento la aspiración democrática para atacar o hacer frente a la situación de la periferia, sino que, hábilmente, la introdujo como ingrediente esencial para alcanzar los fines propuestos.

Este camino no se concibió en el autor como un horizonte utópico a alcanzar sino, más concretamente, lo registró como un trayecto de resistencia, de lo que tuvo que haber sido desde el principio y no fue.

14. Para más información, véase el libro de AGNEW, J.: Geopolítica: una revisión de la política mundial. 2005: Madrid, Trama. 
Una vez articuladas las nociones de desconexión y democracia, el siguiente paso era alentar un crecimiento anti-monopolio/antiimperalista desde abajo. Por ello traza el eje localnacional-mundial ${ }^{15}$, planteando el mismo de la siguiente forma:

a nivel nacional porque sigue siendo el vínculo crucial, porque sigue existiendo una organización política cuyos efectos seguiremos experimentando durante largo tiempo [...]. Estas políticas nacionales requerirán a su vez, para ser suficientemente efectivas, no sólo la reconstrucción de la solidaridad y el apoyo mutuo entre países de la periferia (sobre todo mediante la construcción de uniones regionales), sino también, muy probablemente, transformaciones en las organizaciones económicas y políticas del sistema mundial (Amin, 1992: 57, citado en Corátolo, 2011: 74-75).

Los actores que debían impulsar el cambio se encontraban en todas aquellas fuerzas populares y democráticas que estaban por la labor de revertir la situación neoliberal. Vemos que el remedio sigue haciéndose operativo en la actualidad. Concretamente se refería a los movimientos sociales y a las clases populares/ trabajadoras. Esta apuesta suponía vincular como uno de los elementos determinantes de la resistencia, como bien se sabe por el transcurso de la historia y del pensamiento filosóficopolítico del marxismo clásico pero también del liberalismo (en uno la clase obrera y en el otro el individuo en la sociedad civil), la convicción de que existen sujetos universales que realizan o tienen la capacidad de transformar la historia de manera lineal ${ }^{16}$. Por ello, no era descabellado que hiciese hincapié en la necesidad de apostar por una estrategia política que tuviese como principal ingrediente de la receta lo siguiente:

la integración a escala de América Latina, de África, del mundo árabe, del sudeste

15. Es distinto a la estrategia planteada por Boaventura de Sousa Santos ya que Samir Amin reduce el campo de actuación contrahegemónico o contraimperialista a un mecanismo de desconexión en unas muy concretas zonas mientras que la mirada de Santos es a nivel mundial. Desde las zonas más capitalistas y abiertas al mercado hasta las zonas más castigadas por la desigualdad.

16. Para más información acerca de este debate, creo que debemos de contraponer los textos del marxismo clásico a los de autores como Laclau y Mouffe. asiático, junto a países-continentes (China, India), pero también la de Europa (del Atlántico a Vladivostok), fundada en alianzas populares y democráticas que obliguen al capital a ajustarse a sus exigencias, constituye lo que yo llamo el proyecto de un mundo policéntrico auténtico, otra modalidad de mundialización (Amin, 2001: 26).

Por último y para terminar, Amin identifico también como foco de importancia dentro de la creación de esta lógica contra-mundial, la importancia de la figura de los intelectuales periféricos para la consecución de los objetivos propuestos. En la línea de autores como Amin Maalouf o Ngũgĩ wa Thiong'o, la labor de los intelectuales se hacía primordial para resaltar la vinculación entre teoría y práctica.

\section{EL DESARROLLO SOSTENIBLE DE JEFFREY SACHS}

Sachs se encuentra dentro de aquellos intelectuales occidentales comprometidos con la búsqueda de soluciones universales a cuestiones planetarias como el medioambiente o la pobreza extrema. Por ello ha trabajado en numerosas ocasiones en proyectos de investigación, de instituciones o asociaciones internacionales como la ONU, estando plenamente convencido de que los retos que enfrenta el plantea en el siglo XXI deben de abordarse desde un enfoque mundial.

La propuesta de su teoría del desarrollo sostenible está estrechamente relacionada con el que fue el contenido de los Objetivos del Desarrollo del Milenio del año 2000 de la Cumbre organizada por las Naciones Unidas, sustituido y ampliado casi en su totalidad con la Agenda 2030 de Desarrollo Sostenible ${ }^{17}$. La preocupación por el reto medioambiental, la pobreza y la desigualdad, la falta de desarrollo o estancamiento económico de algunos países y la falta de eficacia y legitimidad de las instituciones políticas han dado pie a que el autor americano proponga un programa políticoeconómico conocido con el nombre de "desarrollo sostenible" con cuatro piezas angulares: un cierto tipo de desarrollo económico, la inclusión social, la sostenibilidad medioambiental y la gobernanza.

17. Para más información acerca de este programa, véase https://www.un.org/sustainabledevelopment/es/2015/09/laasamblea-general-adopta-la-agenda-2030-para-el-desarrollosostenible/. 
La propuesta recuerda, en términos de paralelismo y analogía, pero salvando las distancias en cuanto a propósitos se refiere, al intento refundacional que propuso el filósofo John Ralws con su liberalismo político. Sachs, en su caso, parece querer pretenderlo con un cierto tipo de liberalismo económico. Reacio al sistema depredador neoliberal, podemos catalogarlo como un liberal social o liberal igualitario en el que su teoría sostenible apuesta por un sistema económico internacional de mercado abierto pero asignando un papel primordial y regulador tanto a los organismos internacionales como a los propios Estados.

Estamos frente a un economista muy influenciado por Adam Smith, el cual intenta corregir los desfases del capitalismo actual echando mano de la capacidad de regulación del mismo que tienen las instituciones internacionales y los Estados de cada nación. Es una posición muy cercana a las provenientes de los espectros de la socialdemocracia liberal cómplices con la fragmentación del sistema de bienestar y la apuesta por el neoliberalismo.

En el estudio que lleva a cabo en su libro "La era del desarrollo sostenible" (2015), Sachs (2015:1766) desglosa uno a uno los cuatro puntos nodales a los que hice referencia líneas arriba, estableciendo una serie de objetivos a alcanzar dentro de esta lógica de la sostenibilidad ${ }^{18}$.

El primero de ellos es el desarrollo económico. Comienza su análisis de la economía moderna partiendo de la Revolución Industrial siendo para él el hecho fundamental que nos permite hablar del comienzo de un desarrollo económico moderno. La innovación y la creación en el ámbito tecnológico es fundamental para comprender el progreso del mundo en términos de desarrollo. Si bien es cierto que reconoce que los países occidentales han sido los principales beneficiarios del sistema económico mundial a lo largo de la historia del desarrollo moderno de producción capitalista, no plantea sus intentos de resolución del asunto como lo hacen Amin o la corriente dependentista latinoamericana, siendo más favorable a una economía de mercado mundial con regulación y garantías. La complejidad y dificultad

18. Hay que destacar que estos son los objetivos que entregó a las Naciones Unidas con motivo del encargo que le hizo el que era secretario en su momento de la ONU Ban Ki-Moon. del tema está a la orden del día, precisando de la conjunción y el compromiso de países en cada rincón del mundo, pero se ha de decir, a su favor, es necesario la presencia de autores comprometidos con la búsqueda de un mundo mejor para todos pese al utopismo de esta afirmación, ya que como defiende el americano, las ideas y las aportaciones intelectuales son instrumentos que se adentran dentro de las sociedades y permiten cambiarlas. En esto último no hay ningún tipo de discusión ya que el trabajo intelectual junto con la contingencia histórica son pilares del desarrollo humano.

El tipo de desarrollo que propone se aleja de un patrón incuestionable en el sistema neoliberal de hoy en día como lo es el crecimiento económico, centrándose en desenmascarar ese falso debate que vapulea los datos del PIB a su favor para defender una posición que no tiene en cuenta factores como la sanidad o la educación, y que también influyen en el desarrollo de un país.

En otras palabras, si la mayoría del espectro del intelectualismo económico actual plantea el debate en términos de interacciones comerciales dentro del propio ámbito nacional de cada país o en contextos demográficos más amplios, como puede ser la UE, Sachs (2015:116-123) recuerda que el desarrollo de un país o unión de países no sólo debe centrarse en el papel de consumidor y productor de cada integrante de la sociedad sino que factores como la sanidad, la educación, la natalidad, la felicidad o el bienestar, son olvidados dentro de este tipo de cálculos aun jugando un papel primordial dentro del desarrollo de cada país.

El debate, a su juicio, es tramposo ya que empuja a un escenario donde los países se convierten en meros entes integrantes de personas tenida solamente en cuenta conforme al nivel de productividad tanto en el plano del PNB como en el del PIB. Por ello, el tipo de desarrollo que propone pasa por seguir apostando por el crecimiento económico de cada país pero con unas formas de producción sostenibles con respecto al medioambiente, que sostenga una red de servicios y prestaciones sociales de calidad y eficientes para todos los ciudadanos, una red de transporte centrada en los intercambios comerciales pero también en los desplazamientos de las personas dentro de las ciudades para reducir los niveles de CO2 y la firme apuesta por la promoción 
de la investigación enfocada a la búsqueda de soluciones de sostenibilidad para el mundo.

Conviene recordar que Sachs (2015:567-576) precisa que las peculiaridades de cada país deben de ser tenidas en cuenta para esta estrategia del desarrollo sostenible ya que la misma no puede ajustarse de igual manera a todas las naciones del mundo, por lo que para ello destaca la importancia de contar con lo que él denomina "diagnóstico diferencial". Es una herramienta que permite analizar las circunstancias concretas de cada país y, conforme a ellas, ajustar los parámetros del desarrollo sostenible para remar en la misma dirección. El papel de los organismos internacionales y de la legislación internacional se torna fundamental, llevándonos en última instancia el asunto a un escenario que presenta más de voluntariedad de cooperación de cada país que de otra cosa. Sin ello parece imposible pensar en el triunfo de esta estrategia. El compromiso y la cooperación intergubernamental es la base para que pueda conseguir este tipo de desarrollo.

En este sentido, el autor americano resalta que existen dos opciones de desarrollo. El primero de ellos fue el encabezado por los países occidentales, al cual denomina como "endógeno". Este tipo de desarrollo es heredero de los avances tecnológicos iniciados en Inglaterra con la Revolución Industrial que permitieron obtener tasas de crecimiento económicas bastante positivas junto con la reducción de desigualdades y de situaciones desfavorables para los habitantes de dichos países en términos de generalidad histórica.

En segundo lugar, un modelo de desarrollo que denomina "compensatorio"y el cual es el adoptado por países como Japón o China durante finales del siglo XX llegando hasta nuestros días, que consiste en favorecerse de la apertura a un sistema de libre mercado que permite a estos países beneficiarse de las innovaciones tecnológicas desarrolladas en el exterior a través de la introducción y adaptación de las mismas a sus propias realidades. Es decir, consiste en "renunciar" a un desarrollo tecnológico propio para desarrollar la economía nacional a través de la imitación tecnológica de los mecanismos e instrumentos que han servido a Occidente para alcanzar su posición preeminente. En este sentido es cierto que China, por ejemplo, desarrolla su propia tecnología en campos tan importantes como la nanotecnología o la robótica a través de imitaciones provenientes de EEUU, pero también han comenzado a fabricar sus propios aparatos tecnológicos; buena muestra de ello son las marcas de móviles Huawei o Xiaomi. A este proceso le acuña el nombre de "modelo de los gansos voladores" ${ }^{19}$, triunfante en Asia.

Haciendo un inciso sobre el caso chino, resulta bastante llamativo cómo en la actualidad un gran número de economistas cercanos al dogma neoliberal defienden el crecimiento y desarrollo de China desde 1978 en adelante. Básicamente sus análisis tienen en cuenta la apertura del mercado chino al sistema económico mundial y los beneficios que ello ha reportado a un país que ha desarrollado, innegablemente, una clase media gracias a esta estrategia económica pero que, si ahondamos en lo profundo de este tipo de razonamientos, no hay dedicada ni una sola palabra a cuestiones tan importantes como la ausencia de libertad, de asociación, de expresión, de elección, der participación, en fin, de aquellos que son considerados derechos fundamentales o de primera generación que brillan por su ausencia en un país como China.

Están poniendo como modelo, y conviene resaltar que Sachs lo hace, a un país que no cumple con muchos de los derechos humanos que tanto reclaman desde su posición de intelectuales occidentales. No se pretende con esto catalogar o señalar a China como una especie de monstruo político ya que casi la totalidad de los países del mundo no los respetan, se quiere resaltar que razonamientos demasiado tecnificados como éstos olvidan frecuentemente que la operatividad del capitalismo chino está estrechamente relacionado con un autoritarismo político.

Siguiendo con lo que aquí interesa, este desarrollo sostenible precisa también de inclusión social (equidad). La inclusión social hace referencia en el estudio de Sachs (2015:23-55), por un lado, a la reducción de desigualdades y la

19. Dice Sachs hablando del crecimiento experimentado en países asiáticos como consecuencia del proceso de globalización: "Cuando los gansos vuelan en formación, uno de los gansos vuela delante y los demás siguen su liderazgo. Así es como procedió también el desarrollo económico en Asia, con Japón en primer lugar, y Coreal del Sur, Taiwán, Hong Kong y Singapur volando en formación detrás de él. Detrás de ellos venían Indonesia, Malasia y Tailandia; detrás, China y Vietnam; y ahora, Camboya, Laos y Myanmar" (Sachs, 2015: 128). Japón vendría a ocupar el papel de país con desarrollo endógeno dentro de Asia que es a la vez complementario con respecto a Occidente. 
erradicación de la pobreza y la mortalidad infantil a nivel mundial, siendo millones en la actualidad el número de personas que se encuentran en este tipo de situaciones.

Ello se conseguiría, según el economista norteamericano, no solamente a través de la benevolencia de los países más ricos a través de programas públicos de ayuda al desarrollo, sino que también requiere del acceso a los mercados de los países más desfavorecidos que pasaría, inevitablemente, por el control regulativo de los mercados.

Junto a esta primera inclusión económica, resalta Sachs una segunda que tiene que ver con la integración del capital humano de las mujeres y de las minorías étnicas. Esta integración la plantea tanto en términos de aprovechamiento productivo como en un plano de enriquecimiento cultural de la esfera pública e igualdad entre hombres y mujeres, puesto que sin ello no es posible materializar la consecución de un mundo sostenible y sostenido. En este sentido, tanto cultura como economía son concebidas por el economista americano como estructuras no monolíticas, por lo que hay posibilidad de acción en una u otra dirección y margen de maniobra para hacer las cosas de otra forma. Los tiempos de globalización penetran en cada una de las esferas que ocupa nuestra vida por lo que, y este razonamiento es bastante similar al que hacen Negri y Hardt ${ }^{20}$ (2002), la respuesta a dicha forma político-económica puede/debe darse desde lo inmanente de cada una de ellas. No es que Sachs sea partidario de la deconstrucción del sistema económico liberal ni muchos menos, sino que objeta la necesidad de intervención pública de este para garantizar unos mínimos humanos a nivel mundial.

La preocupación por el medioambiente y la protección de la biodiversidad es el tercer punto del desarrollo sostenible. Este apartado queda

20. En este libro ambos autores se encargan de formular una propuesta filosófico-política consistente en la recuperación del concepto de multitud propuesto en su día por Spinoza. A través del mismo plantean la posibilidad de hacer frente al enemigo (El Imperio) con la conjunción de una multiplicidad de singularidades que se manifiesta en esta nueva época caracterizada por el desarrollo tecnológico y el trabajo en el sector servicios, el cual, resaltan los autores, se caracteriza por un trabajo de corte intelectual o cerebral que denominarán Genera Intellect. Para más información acerca del asunto, véase: NEGRI, A. y HARDT, M.: Imperio. España: Paidos Ibérica, 2002. íntegramente relacionado con los restantes, pero cobra especial importancia con respecto al modelo productivo de desarrollo económico reinante en la actualidad. Los límites planetarios, en opinión de Sachs (2015: 220-250), están siendo rozados con los dedos por la humanidad. El modelo productivo basado simplemente en la acumulación de beneficios para las empresas multinacionales, el escaso compromiso de los gobiernos nacionales de los distintos países y la contaminación generada por las emisiones de $\mathrm{CO} 2$ han llegado a un punto preocupante que requiere de una mejor regulación a nivel internacional de la materia (como ha puesto de manifiesto la Cumbre de París o las actuaciones del Presidente de los EEUU Donald Trump).

El compromiso tanto del sector público como del privado debe de ser firme y transparente con el medioambiente. No hay que renunciar a un modelo de producción capitalista que tenga el beneficio por principal objetivo pero sí que se hace necesario que se desarrollen mecanismo jurídicos de regulación para controlar y castigar a aquellos que contaminen o dañen la biodiversidad. Esta preocupación es compartida con Boaventura de Sousa Santos, como veremos más adelante, pero este último intenta dar respuesta mediante la formulación de la posibilidad de surcar caminos de producción no capitalista.

Uno de los planteamientos más interesantes y controvertidos que hace el autor dentro de este tercer punto muestra la necesidad de controlar el ritmo de crecimiento de la población ya que cada vez somos más personas en el planeta y ello genera mayor producción/consumo para más población, dando paso a la creación de grandes abastecimientos ganaderos y explanadas agrícolas que ponen en peligro la seguridad alimentaria con el uso de pesticidas y plaguicidas para acelerar los ritmos de crecimiento del ciclo económico para producir en grandes cantidades. En este sentido, al igual que en campos como la sanidad y la educación, el compromiso público es fundamental para alcanzar las metas de la sostenibilidad. De nuevo, la retórica de la sostenibilidad debe de imponerse a la de acumulación de beneficio.

Esto último nos prepara para abordar el cuarto y último punto del planteamiento angular del marco teórico del economista: la gobernanza. Con este término, recuerda Sachs (2015:162168), que no sólo debemos entender el derecho a 
tener un gobierno que ayude a mejorar nuestras vidas y garantice nuestra seguridad lo máximo posible, sino que incluye un compromiso ético y de transparencia por parte de las instituciones públicas para con sus ciudadanos y un mayor compromiso en términos de participación de estos últimos con respecto a las instituciones.

De nuevo, la importancia y voluntariedad de lo público-institucional se vuelve primordial dentro de su argumentario, añadiéndose también el rol de la sociedad civil. No aclara si dicha preeminencia guarda relación con la dificultad actual de llegar a acuerdos en las asambleas legislativas de los distintos países con motivo de la creciente heterogeneidad que las asola o si es que los objetivos de su propuesta precisan indiscutiblemente de un fuerte ejecutivo que, conviene tener en cuenta, corre el riesgo de asumir cada vez más poder y control sobre los aparatos estatales creando la posibilidad de dar lugar a situaciones autoritarias.

Al fin y al cabo, el modelo que tiene en la cabeza es bastante cercano a las socialdemocracias escandinavas, las cuales, como bien puso de manifiesto Linz (1987:232-285) en su estudio sobre las crisis de las democracias en la Europa de entreguerras, ostentan una legitimidad histórica e institucional por parte de sus ciudadanos que les hicieron alejarse de extremismos tanto de izquierdas como de derechas, a diferencia de muchos otros países de la órbita europea.

Como indiqué al comienzo de este epígrafe, los ODM (Objetivos de Desarrollo del Milenio) son el punto inicial sobre el que el autor incoó su camino de elaboración de lo que denominó los ODS (Objetivos del Desarrollo Sostenible) ${ }^{21}$.

21. Estos objetivos son diez y fueron objeto de un trabajo que se le encargó al propio Sachs por parte de la ONU para alcanzar la meta de la sostenibilidad en el presente siglo XXI. Son diez los objetivos que el americano formuló como recomendaciones para este milenio y serían los siguientes: acabar con la pobreza extrema, incluida el hambre; lograr el desarrollo dentro de los límites planetarios; garantizar un aprendizaje efectivo para todos los niños, niñas y jóvenes para su vida y sustento; alcanzar la igualdad de género, inclusión social y derechos humanos para todos; lograr salud y bienestar en todas las edades; mejorar los sistemas agrícolas y elevar la prosperidad rural; empoderar a las ciudades inclusivas, productivas y resilientes; frenar el cambio climático inducido por el hombre y garantizar enegergía sostenible para todos; garantizar servicios y biodiversidad del ecosistema, así como una buena gestión de los recursos hídricos y otros recursos naturales $y$, por último, transformar la gobernanza del desarrollo sostenible. Para más información acerca del desarrollo de dichos objetivos, véase: SACHS, Jeffrey.
Estos objetivos precisan de dos herramientas primordiales: la retroproyección y las hojas de ruta tecnológicas. El primero de ellos consiste en lo siguiente:

en lugar de tratar de anticipar lo que ocurrirá en 2040 o 2050, la retroproyección consiste en marcar un objetivo para una determinada fecha futura y luego analizar la relación entre este objetivo y la situación presente hasta diseñar una trayectoria que permita conseguirlo. La retroproyección consiste en preguntar: ¿Cómo podemos llegar hasta allí? (Sachs, 2015: 573).

La segunda herramienta, las hojas de ruta tecnológicas, son los instrumentos de los que se echará mano para comprobar los obstáculos y las cordilleras que se han de superar en el ámbito de las tecnologías para alcanzar el objetivo de la sostenibilidad. Las barreras tienen que ver con sectores como el energético donde el papel de las energías renovables, el almacenamiento de energía solar y eólica, servicios alternativos y creación de nuevas redes de conexión eléctrica entre diferentes lugares se presentan como intermitentes y se afrontan con incertidumbre. Por ello, dichas rutas ayudan a prepararse para el reto tecnológico, siendo básico que el uso de las mismas se haga en beneficio del interés general y no bajo la lógica capitalista de acumulación.

Recordemos que la tecnología, si bien es un arma que puede mejorar la productividad y la autonomía de las personas, también puede influir de manera negativa sobre las mismas, como bien se pone de manifiesto en sectores como el laboral ${ }^{22}$.

A fin de cuentas, y en términos generales, este el modelo teórico que propone Sachs como respuesta a los tiempos actuales. Ejemplos como el de los países asiáticos avalan muchos de sus argumentos en términos de desarrollo económico

La era del desarrollo sostenible. Barcelona: Deusto, 2015.

22. Con ello me refiero a la posibilidad que desencadenan el mal uso de las nuevas tecnologías, por ejemplo, en el ámbito laboral por el uso abusivo o incorrecto que los empleadores hacen de sistemas tecnológicos como por ejemplo la videovigilancia empresarial o la geolocalización. Los dispositivos tecnológicos pueden afectar tanto a los derechos laborales como a los derechos fundamentales de de los trabajadores en los centros de trabajo o durante el desarrollo de la prestación laboral. Es, a fin de cuentas, un arma de doble filo que está presente en todos los ámbitos de nuestra existencia. 
y reducción de niveles de desigualdad y pobreza, olvidando en numerosas ocasiones a cuenta de qué. Su astucia recuerda, de manera acertada, que los modelos no son exportables pero sí adaptables. En definitiva, piensa más como lo que es: un economista. Ello le hace tener momentos en los que pareciera colocar el desarrollo a cualquier precio y por encima de todo. De todas formas, es innegable su compromiso para construir un mundo más justo y equitativo donde todos tengamos cabida y podamos convivir en armonía con el resto de gentes y con la naturaleza.

Por lo tanto, el derecho al desarrollo en la teoría de Sachs consiste en asumir que el mundo globalizado en el que vivimos precisa de respuestas internacionales, por lo que la apuesta por una especie de cosmopolitismo kantiano vuelve a resurgir con fuerza de la mano de este autor. La política económica mundial debe de refutar el dañino dogmatismo que defiende que el mercado se regula a sí mismo, dando paso a la coordinación entre Estados y organismos internacionales que regulen la economía para garantizar unos mínimos comunes básicos.

Al igual que hizo Rawls, Sachs pone en entredicho el capitalismo actual mediante el cuestionamiento del principio de distribución de los beneficios, contribuyendo al debate de que el liberalismo no olvide el plano social dentro de sus análisis.

\section{4.¿DESARROLLO 0 LIBRE DETERMINACIÓN?: LA APORTACIÓN DE BOAVENTURA DE SOUSA SANTOS}

En este último apartado se trabajarán las ideas que nos brindan los escritos del pensador luso Boaventura de Sousa Santos acerca de la problemática entre el derecho al desarrollo y el derecho a la libre determinación en las numerosas regiones que componen África, Asia y América Latina. No es casualidad que los continentes donde se encuentran los mayores porcentajes de desigualdad, de pobreza y de dificultades con respecto a bienes de primera necesidad hayan sido y son, a día de hoy, escenario de conflicto social.

El derecho colectivo al desarrollo está intrínsecamente relacionado para Santos con la filosofía del movimiento de los No-Alienados. Este conjunto de países comenzó a reivindicar durante la segunda mitad del siglo XX el derecho a un desarrollo de carácter autónomo que no les empujase a tener que elegir entre unirse al bloque comunista o al bloque capitalista. Dentro de esta reivindicación se puso de nuevo encima de la mesa el asunto del intercambio desigual. La situación internacional colocaba a los países de la periferia y semiperiferia como meros peones o reos de las políticas que beneficiasen a cualquiera de los dos bloques. La caída de la URSS y del modelo socialista fue para Santos (2014:68) el hecho que propició la consolidación del modelo neoliberal que venía gestándose desde los años setenta en el bloque capitalista. Ello supuso la conversión del derecho al desarrollo en el deber de desarrollarse.

$\mathrm{Al}$ igual que Amin, Santos concibe esta nueva etapa o ciclo con una radicalidad y autoritarismo económico desmesurado. Los costos sociales de este tipo de desarrollo neoliberal hacen que cada vez haya más especulación financiera, mayor degradación medioambiental, políticas antisociales y un exceso de atención al crecimiento económico. Todo ello le da pie a catalogar esta situación como de fascismo social ${ }^{23}$.

En este sentido, entrado el siglo XXI este modelo reúne una serie de características que conviene tener en cuenta: en primer lugar, el papel de los BRICS $^{24}$ como países emergentes (sobre todo la importancia de China a día de hoy); en segundo lugar, el desarrollo capitalista está llegando a alcanzar el límite de carga que el planeta puede soportar como consecuencia de su

23. En esta nota añado una breve y general definición que el pensador luso hace de este concepto. Dice Santos (2009: 560) de lo que entiende por fascismo social: "Con ello no se está hablando de un regreso al fascismo de los años 30 y 40 del siglo pasado. A diferencia del anterior, el fascismo actual no es un régimen político. Es más bien un régimen social y civilizacional. En ligar de sacrificar la democracia a las exigencias del capitalismo, trivializa la democracia hasta el punto que ya resulta innecesario, ni siquiera conveniente, sactificar la democracia a fin de promocionar el capitalismo. Se trata de un tipo de fascismo pluralista producido por la sociedad en lugar del Estado. E Estado es aquí un testigo complaciente, cuando no un culpable activo. Estamos entrando en un período en el que los Estados democráticos coexisten con las sociedades fascistas. Es por tato un fascismo que nunca había existido". Para más información acerca del asunto, véase: SANTOS, B.: Sociología jurídica crítica. Para un nuevo sentido común en el derecho. Madrid: Trotta, 2009.

24, Estas siglas hacen referencia a los países de Brasil, Rusia, India, China y Sudáfrica. Conviene precisar que la situación ha cambiado un poco con motivo de la pérdida de fuerza de Brasil y del importante papel a nivel mundial que está adquiriendo China, disputándole el papel de hegemón a EEUU. Este último hecho queda palpable en las políticas anti-China que está llevando a cabo el presidente Donald Trump en materias como la teconología móvil. 
sistema productivo, de comercio y de consumo (talas de árboles, explotaciones ganaderas y agrícolas, etc.) ; y, en tercer lugar, la llegada de gobiernos progresistas en América Latina (de los cuales muchos ya han dejado de existir o están en situación de alarma social) auspiciados por movimientos $\mathrm{y}$ asociaciones sociales han amoldado el modelo neoliberal a sus exigencias nacionales dando lugar a lo que se conoce como "neoextractivismo" o "neodesarrollismo"25, aun habiéndose proclamado en un primer momento como enemigos del desarrollo (Santos, 2014: 69-71).

Estas tres peculiaridades dan paso a una multiplicidad de matices en el seno de la tensión entre derecho al desarrollo y el derecho a la libre determinación, pero me centraré en las tres que considero más determinantes para esta labor. Concretamente haré hincapié en la tensión generada con respecto a los derechos ambientales y el derecho a la salud; la tensión entre el desarrollo neoliberal y la libre determinación de los pueblos indígenas; $\mathrm{y}$, finalmente, la tensión entre el derecho al desarrollo y el derecho de los pueblos a librarse del colonialismo y neocolonialismo. Al igual que Sachs, Santos muestra preocupación por las circunstancias ambientales y sanitarias que provoca el desarrollo capitalista actual con motivo de su voracidad y ansia de acumulación de beneficios.

El modelo de desarrollo agrícola conocido con el nombre de agroindustria, presente en numerosas zonas de América Latina para la obtención de productos como la soja, el azúcar,

25. Con este término se define al conjunto de políticas que han llevado casi la totalidad de los gobiernos progresistas que alcanzaron el poder a comienzos del siglo XXI en América Latina y que tienen como característica principal el acomodo de políticas progresistas relacionadas con la nacionalización de los recursos naturales y la redistribución de la riqueza. Presidentes como Chávez, Evo Morales, Rafael Correo, etc, se presentaron como fuerzas contrarias al tipo de desarrollo neoliberal reinante en el mundo para dar paso no ya a un desarrollo autónomo sino, más bien, a lo que podríamos denominar alternativas al desarrollo. Como se ha visto durante la experiencia de estos gobiernos, lo que antes era explotado por las multinacionales americanas o europeas ahora ha pasado a manos del Estado, lo cual ha permitido sacar a miles de personas de situaciones de pobreza como sucedió durante el mandato de Lula Da Silva. Ello no es motivo para criticar que, como hace Santos, aprovechando los altos precios a los que estaban los barriles de petróleo durante los primeros años de este milenio, las políticas de estos gobiernos se han quedado restringidas al aprovechamiento de los recursos naturales sin ningún tipo de plan b y, en numerosas ocasiones, sin respetar lo dispuesto en sus respectivas constituciones para con los pueblos más vulnerables como son los cimarrones y los indígenas. algodón y tabaco, precisa del uso de pesticidas que afectan tanto a la tierra como a los alimentos que posteriormente consumimos. De nuevo, la vuelta a la economía de los productos primarios no es motivo para criticar que, como hace Santos, aprovechando los altos precios a los que estaban los barriles de petróleo durante los primeros años de este milenio, las políticas de estos gobiernos se han quedado restringidas al aprovechamiento de los recursos naturales sin ningún tipo de plan b y, en numerosas ocasiones, sin respetar lo dispuesto en sus respectivas constituciones para con los pueblos más vulnerables como son los cimarrones y los indígenas. vuelve a ser una realidad para los países de la periferia y semiperiferia.

Las inversiones procedentes de países como China o Arabia Saudita en lugares como Etiopía o Benín para la producción de arroz o azúcar a través de la compra de tierra fértil es una realidad. Ello trae consigo un desplazamiento de prácticas locales de trata de la tierra que no tienen cabida cuando se topan con las inversiones gigantescas como las de estos Estados o grandes multinacionales. La salud también queda atravesada por este problema, provocando que enfermedades como el cáncer, problemas dermatológicos y de respiración estén a la orden del día en aquellas regiones donde el uso y consumo en alimentos de pesticidas o plaguicidas es abundante. No es casualidad que regiones como Mato Grosso o Sao Paulo sean los mayores consumidores de pesticidas del planeta.

Este tipo de industria agrícola representa un importante segmento de la economía de muchos de estos países, lo que se traduce, a su vez, en poder político presente en las Asambleas Legislativas. Ello complica, en numerosas ocasiones, la posibilidad de aplicar políticas reversivas desde el centro del poder político. De ahí que, la gran esperanza de cambio, provenga de los movimientos sociales, ONGs, agrupaciones o asociaciones de campesinos y numerosos colectivos que hacen resistencia a este tipo de prácticas y que, además, en algunas ocasiones, llevan a cabo formas de producción de carácter alternativo.

En este sentido, en su libro "Producir para vivir. Los caminos de la producción no capitalista" (2002), el luso fue coordinador de un proyecto académico donde se mostraron numerosos ejemplos de desarrollo alternativo 
o de alternativas al desarrollo que coexisten con el sistema capitalista actual ${ }^{26}$. Ejemplos como las cooperativas de Mondragón, los recicladores/as de basura en Colombia o India, los campesinos sudafricanos y la economía solidaria en Brasil de la mano del Movimiento de los Sin Tierra (MST), son ejemplos de producción alternativa al capitalismo actual que asientan su base en dos pilares básicos: la igualdad y la solidaridad.

Las redes de ayuda mutua en la formas asociacionistas o cooperativistas con otros entes como los sindicatos y, alguna que otra vez con el Estado o empresas capitalistas, son una realidad que dejan abierta una puerta de esperanza para hacer las cosas de otra manera.

Lo interesante del cooperativismo como forma de producción alternativa es que se aparta tanto del socialismo centralizado de corte soviético como de la depredación neoliberal preocupada únicamente por el beneficio ${ }^{27}$. Estas diferentes formas de producción es posible que se ajustasen de una mejor manera a la sostenibilidad medioambiental y contribuirían a la extensión de la participación democrática al campo económico.

El segundo matiz hace referencia a la situación en la que se encuentran muchos de los pueblos indígenas en la actualidad. El modelo de empresa multinacional supone el trastocamiento de las formas de vida de estos colectivos. La concentración de tierra necesaria para llevar a cabo explotaciones agroindustriales o ganaderas, la construcción de carreteras que atraviesen zonas protegidas, el acceso a la explotación de recursos

26. La diferencia en este punto radica en que el desarrollo alternativo tiene más que ver con la búsqueda de prácticas o actuaciones que vayan encaminadas menos a la acumulación o beneficio y más centradas en la solidaridad y la justicia dentro de un marco capitalista. Las alternativas al desarrollo, que no difieren en gran cantidad de lo que es el desarrollo alternativo, tienen más que ver con las posiciones o propuestas anticapitalistas, de deconstrucción del modelo.

27. En este sentido, conviene acudir al libro mencionado ya que los numerosos casos o ejemplos que se desarrollan en el mismo son desconocidos o han pasado desapercibidos en numerosas ocasiones. Este tipo de prácticas están siendo cada vez más habituales sobre todo en zonas rurales pero también en centros de ciudades como puede ser el modelo cuasi-cooperativista de los trabajadores de Volkswagen o los trabajadores de Viome en Grecia. La autogestión va camino de convertirse en una realidad del siglo XXI. Para más información, véase: DE SOUSA SANTOS, Boaventura. Producir para vivir. Los caminos de la producción no capitalista. Brasil: Civilizaçao Brasiliera, 2002. Con respecto al caso de las empresas, véase: http://periodicoellibertario. blogspot.com $/ 2017 / 08 /$ grecia-trabajadores-salvan-suempresa.html naturales y la edificación de presas hidráulicas suponen el desplazamiento o la ocupación de las zonas habitadas por estas tribus. Estos hechos no solamente dañan la biodiversidad y la naturaleza sino que, también, acaban generando conflictos sociales en los que, en el peor de los casos, se produce la muerte de campesinos o activistas sociales.

Esta resistencia al beneficio del capital y a la connivencia de numerosos gobiernos es una realidad ${ }^{28}$ innegable. Ni la protección constitucional de dichos pueblos y de sus asentamientos ha conseguido frenar el conflicto entre la acumulación capitalista y el modelo de vida tradicional indígena preocupado por el respeto y cuidado de la naturaleza.

Para Santos (2014: 80-93), la lucha indígena supone una forma de resistencia a la opresión neoliberal que debe de aunarse y tejer redes de apoyo mutuo con otras formas de resistencia como son la lucha ecologista o feminista anticapitalista ${ }^{29}$.

Finalmente, el último lugar traigo a colación el derecho a librarse del colonialismo o neocolonialismo de los diferentes pueblos de la periferia y semiperiferia del mundo. Si la independencia política es una realidad para todos aquellos países que estuvieron bajo dominio político colonial, no puede decirse lo mismo con respecto al plano económico.

Santos nos muestra, echando mano de los estudios de Marini, que el neocolonialismo es una realidad que afecta tanto al ámbito privado como al sector estatal, capaz de mutar en una especie de subimperalismo basado en la cooperación antagónica entre los poderes hegemónicos occidentales y el papel que desempaña, por ejemplo, Brasil dentro del continente latinoamericano. En este sentido, y

28. Casos como los de Bolivia o Ecuador que han acabado en los tribunales de la Corte Interamericana de Derechos Humanos con motivo del enfrentamiento entre los pueblos indígenas y el Gobierno son claros ejemplos de la consolidación del modelo extractivista y agroindustrial. Para más información acerca de este asunto, véase: SANTOS, B.: Derechos humanos, democracia y desarrollo. Bogotá: Dejusticia, 2014. pp. 80-93.

29. Utilizo el término anticapitalista porque dentro del movimiento feminista existen corrientes que apuestan claramente por no abandonar un sistema capitalista ya que simplemente muestran su intención en relación con el mayor incremento de mujeres que entren a formar parte de la estructura económica, mostrándos alejadas de cuestionamientos anticapitalistas. 
parafreaseando al pensador portugués, los nuevos tiempos generan nuevas formas presentes en la realidad fáctica de la siguiente manera:

subimperialismo es la forma que toma tanto la economía dependiente al llegar a la etapa de los monopolios y del capital financiero. El subimperialismo tiene dos componentes básicos: en primer lugar, una composición orgánica (del capital) media en la escala mundial de las estructuras productivas nacionales $\mathrm{y}$, en segundo lugar, el ejercicio de una política expansionista relativamente autónoma, que no solo va acompañada de una mayor integración con el sistema productivo imperalista, sino que se mantiene en el marco de la hegemonía ejercida por el imperalismo internacional. Expresado de esa forma nos parece que, con independencia de los esfuerzos de Argentina y de otros países por llegar al nivel subimperalista, solo Brasil expresa de forma plena un fenómeno de esta naturaleza en América Latina (Marini, 1977: citado en Santos, 2014: 95).

Lo que para Marini y Santos son nuevas formas de connivencia con el capital financiero internacional bajo el bastón de países como Brasil, Japón o China dentro de sus respectivos continentes, para Sachs, como vimos anteriormente, son ejemplos de superación y triunfo dentro del modelo de adaptación mediante el desarrollo compensatorio.

En este sentido, la influencia y preeminencia de un determinado país dentro de la región a la que pertenece se convierte en un problema en el momento en el que las empresas públicas estatales $o$ las privadas nacionales ejercen presión o condicionan las políticas de otros países vecinos. Sin ir más lejos, ahí están los ejemplos de la constructora brasileña OAS en Bolivia para la construcción de una autopista que atraviesa la zona del Tipnis o de la explotación de carbón en Mozambique por parte de la empresa Vale do Rio Doce $^{30}$.

30. En el primero de los casos, la Constitución plurinacional de Bolivia recoge la protección de los pueblos indígenas y sus tierras junto con la obligatoriedad de llevar a cabo una consulta previa a los mismos en antes de llevar a cabo cualquier tipo de actuación que suponga la afectación del territorio o de la vida tradicional de estos pueblos. Ello no se cumplió en el caso de Bolivia, pese a estar en el poder, ni más ni menos, que un indígena como es Evo Morales. Todo ello supuso un conflicto social que se materializó en la famosa Marcha Indígena IX. El segundo también es una claro
Todo lo anterior pone en el punto de mira la necesidad de atacar frontalmente lo que denomina como "fascismo desarrollista"31, el cual, es una pieza más dentro de la conjunción o combinación de prácticas e instituciones democráticas con diferentes tipos de autoritarismos (como el financiero). En este sentido, formas alternativas de desarrollo como el swadeshi ${ }^{32}$ gandiano o la teoría cooperativista incoada en el siglo XIX por Proudhon y visible en nuestros días en numerosas experiencias como las citadas anteriormente, se presentan como posibilidades de aprendizaje que pueden quedar entroncadas en la lucha por un nuevo horizonte político. La estrategia contrahegemónica debe de articularse en sentido de escala, es decir, de lo local a lo global pasando por lo nacional para conjugar un cosmpolitismo subalterno ${ }^{33}$.

ejemplo de connivencia gubernamental entre el Estado brasileño y el Gobierno de Mozambique e intereses económicos. En el caso de los países africanos se muestra de manera más fehaciente la estrecha relación entre esferas del poder político y el poder económico ya que son numerosos los dirigentes de países que, a la vez que están en posiciones políticas privilegiadas, cuentan con empresas que se benefician de la inversión extranjera. A fin de cuentas, este subimperialismo funciona con las mismas lógicas de mercado que lo hacen las empresas transnacionales. Para más información acerca de estos ejemplos, véase: SANTOS B.: Derechos Humanos, democracia y desarrollo. Bogotá: Dejusticia, 2014. Un punto de vista contrario acerca del conflicto y del caso boliviano lo da el mismo Vicepresidente del país en uno de sus libros. Por ello, véase: GARCÍA LINERA, A.:El "Oenegismo", enfermedad infantil del derechismo. (O cómo la "reconducción" del Proceso de Cambio es la restauración neoliberal). La Paz, Bolivia. 2013.

31. Lo define Santos (2014:103) de la siguiente manera: "Si la depredación de los recursos naturales y la tierra que hace este modelo de desarrollo sigue influyendo en los Estados y los gobiernos democráticos, por un lado, para que estos hagan tabula rasa de los derechos de la ciudadanía y los derechos humanos, incluidos los consagrados en el derecho internacional $y$, por otro lado, para reprimir de manera brutal e impune a todos los que se atreven a resistirse a ese modelo, es posible que estemos ante una nueva forma de fascismo social: el fascismo desarrollista".

32. Lo define Santos (2014:103) de la siguiente manera: "Si la depredación de los recursos naturales y la tierra que hace este modelo de desarrollo sigue influyendo en los Estados y los gobiernos democráticos, por un lado, para que estos hagan tabula rasa de los derechos de la ciudadanía y los derechos humanos, incluidos los consagrados en el derecho internacional $y$, por otro lado, para reprimir de manera brutal e impune a todos los que se atreven a resistirse a ese modelo, es posible que estemos ante una nueva forma de fascismo social: el fascismo desarrollista".

33. Dice Santos (2002:65-66), hablando de este tipo de cosmpolitismo que "Las formas predominantes de dominación no excluyen la posibilidad para Estados-nación, regiones, clases o grupos sociales y sus aliados de organizarse transnacionalmente en defensa de intereses que se perciben como comunes, y de usar en su beneficio las capacidades para la interacción transnacional creadas por el sistema mundial. Las actividades cosmopolitanas incluyen, entre otras, diálogos y organizaciones Sur-Sur, nuevas formas de internacionalismo 
La tensión entre el derecho al desarrollo y el derecho a la libre determinación de los pueblos queda atravesada inevitablemente, en una de sus caras, por la lucha contrahegemónica en el terreno de los derechos humanos ${ }^{34}$. El sostenimiento del planeta y la supervivencia de la especie animal y humana requieren de un modelo de desarrollo económico de intercambio y acceso al mercado (en este sentido el mercado no se entiende en términos de intercambio desigual entre países, ya que mercado y capitalismo han acabado significando lo mismo cuando no es así) que se preocupe más por producir para sobrevivir que en la creación de deseos irracionales, permitiendo que todos los pueblos tengan derecho a un futuro autónomo, y si es posible, unidos en la consecución de un mundo mejor.

Por ello, la teoría democrática republicana en última instancia debe de extenderse a un modelo participativo, de diálogo entre los ciudadanos y las instituciones a nivel local, nacional y global. Lo mismo debe de ocurrir en el ámbito de la cultura o las ciencias como bien se ha encargado de estudiar Santos (2006). Todo ello debe de tener en cuenta una cosa: el camino es pedrejoso y complicado, lleno de obstáculos, con un horizonte utópico fuerte pero responsable, es decir, ya no hay que esperar a que existan unas condiciones objetivas

laboral, redes transnacionales de grupos de mujeres, de pueblos indígenas y organizaciones de derechos humanos, servicios legales alternativos transfronterizos, solidaridad Norte/Sur anticapitalista, ONG de abogacía transformativa, redes de desarrollo alternativo y grupos de medio ambiente sostenible, movimientos literarios, artísticos y científicos en la periferia del sistema mundial en busca de valores culturales no imperialistas, y mucho más. A pesar de la heterogeneidad de las organizaciones involucradas, la contestación a la reunión de la Organización Mundial del Comercio en Seattle (noviembre 30 de 1999) fue un buen ejemplo de lo que llamo cosmopolitismo". Mientras que de la herencia común de la humanidad resalta que "Éstos son asuntos que sólo tienen sentido como referidos al globo en su totalidad: la sostenibilidad de la vida humana en la Tierra por ejemplo, y asuntos semejantes como la protección de la capa de ozono, del Amazonas, de la Antártica, de la biodiversidad del lecho marino profundo. Además, incluiría en esta categoría la exploración del espacio exterior, de la luna y de otros planetas, dado que las interacciones de estos últimos con la Tierra forman parte también de la herencia común de la humanidad. Todos estos asuntos se refieren a recursos que, por su misma naturaleza, deben ser administrados por fideicomisarios de la comunidad internacional en beneficio de las generaciones presentes y futuras".

34. Con ello pone de manifiesto que la teoría de los derechos humanos ha conseguido ir ocupando un espacio de interés cada vez más notable en los ámbitos del movimiento socialista, llegando incluso a renunciar a algunas de las metas del mismo para dar paso a los derechos humanos. En este sentido, es fehaciente que estamos más en tiempos de contención que en tiempos de profundización, teniendo como principal meta no dejar escapar los logros anteriores. de posibilidad como creía el marxismo clásico o el estructuralismo de finales del siglo XX, sino que el trabajo debe de ser desde ya mismo, con un claro marco utópico esperanzador pero que advierta que el futuro también puede ser incierto para no crear demasiadas esperanzas. Es, a fin de cuentas, como decía Bloch, un todavía no pero que ya ha iniciado el camino para convertirse en un sí a través de las diferentes luchas que recorren el planeta.

\section{CONCLUSIONES}

Este trabajo ha intentado ser un recorrido histórico desde la lupa de algunos autores de la tensión existente entre el derecho al desarrollo y el derecho a la libre determinación de los pueblos en el sistema político internacional. El dogma económico liberal capitalista internacional que aseguraba el beneficio para todos los países que entrasen a formar parte del mismo ha sido cuestionado desde los años cincuenta del siglo. Ello no quita para afirmar que es cierto que un acceso a dicho mercado supone, en un sentido general, más beneficios que perjuicios en comparación con un sistema de aislamiento. Nadie puede negarse a día de hoy a no participar de la economía mundial. Además, la economía de mercado no es el problema ni mucho menos, el problema es que la misma quede capitalizada más por una ideología que piense más en hiperfinanciarizar y acumular beneficio que en los intereses generales. El intercambio comercial entre regiones ha sido una constante a lo largo de la historia que ha trabajado en beneficio de la prosperidad de los sujetos, habiendo sido desvirtuado el mismo mediante las lógicas hiperindividualistas del consumo. Por ello, propongo volver a recuperar una idea de economía de mercado en la que se piense tanto en el beneficio como en el bienestar general, donde se combine la libertad con la regulación.

La tónica que se ha pretendido mostrar en este quehacer ha consistido en intentar dar pie a un debate donde se ponga encima de la mesa si el derecho de autodeterminación consagrado en la Declaración Universal de los Derechos Humanos de 1948 debe de quedar restringido a la imitación de los modelos de desarrollo de los países occidentales o si, por el contrario, debe de darse paso a surcar la posibilidad de mecanismos alternativos. Las experiencias de algunos gobiernos progresistas en América Latina muestran una amalgama de sensaciones 
contradictorias a este respecto. Lo que está claro y que está presente en este estudio es que el desarrollo neoliberal está cada vez más empujando a un escenario de crisis civilizacional que tiene como principal y temible consecuencia la destrucción del planeta. Las talas de árboles, el incremento de fenómenos meteorológicos destructores, el uso de pesticidas y plaguicidas que dañan la salud, los asentimientos agroindustriales y explotaciones ganaderas, la construcción de presas hidráulicas y carreteras en zonas reservadas, la explotación de los recursos naturales hasta máximos históricos, entre otros, hacen que nos enfrentemos a problemas de escala global que deben de tener respuestas coordinadas.

Desde la teoría estructuralista que inició su teoría crítica fruto del intercambio desigual, poniendo encima de la mesa como solución un desarrollo autónomo de la región latinoamericana, la corriente dependentista expandió el estudio del sistema económico internacional al plano cultural y sociológico de las distintas sociedades, la radical propuesta de desconexión de Samir Amin que tiene como fundamento último adecuar el desarrollo de cada país a las necesidades nacionales y no a las exigencias externas, la regulación del mercado capitalista con una fuerte intervención "desde arriba" para alcanzar el desarrollo sostenible en Sachs, hasta la llegada al cosmopolitismo subalterno de Boaventura de Sousa Santos, el derecho al desarrollo se ha mostrado como un asunto al que se le dan diferentes respuestas desde distintos espectros del pensamiento político.

Ello ha contribuido a enriquecer el debate en términos académicos y acelera la búsqueda de soluciones (más o menos reales) a las vivencias actuales. Conviene no olvidar que cada una de las aportaciones que se ha hecho a este tema deben tomarse en serio ya que las propuestas de la dimensión de las aquí estudiadas pueden ser determinantes en el día de mañana. La conexión entre políticas institucionales y trabajo académico no están tan alejadas como a veces pensamos.

En este sentido, este trabajo ha querido en última instancia, destacar la teoría política de Boaventura de Sousa Santos con respecto al tema tratado, tomando para ello un punto de vista tanto cronológico como diferencial en lo ideológico. Por ello, la "solución" contrahegemónica que elabora tiene mucho que ver con las experiencias que han revitalizado la política de alternativas en lugares tan distantes como Kerala, Mozambique o Portugal y que, conviene apuntar, encuentra acomodo intelectual en los encuentros acaecidos bajo el Foro Social Mundial.

Por todo lo anterior, el derecho al desarrollo y el derecho a la autodeterminación han llegado a la discusión académica y política para quedarse. Siguen y seguirán estando en el centro del debate político, se nutrirán, adaptarán, actualizarán y rechazarán propuestas y soluciones llegadas desde el centro del poder político pero también desde los sistemas universitarios y los círculos intelectuales. La complejidad y la dificultad son insalvables pero la disputa y el consenso seguirán enriqueciendo un debate que necesita de mucha atención, más por los grandes retos que tiene la humanidad por delante en ámbitos como el medio ambiente, las desigualdades sociales o la redistribución de la riqueza.

\section{BIBLIOGRAFÍA}

- Agnew, J. (2005). Geopolitica: una revisión de la política mundial. (M. Lois, Trad.) Madrid: Trama.

- Amin, S. (s.f.). Capitalismo, Imperialismo, Mundialización. CLACSO, 15-29.

- $\quad$-----.(1992). El capitalismo en la era de la globalización. Barcelona: Paidós.

- ----.(1986). El desarrollo desigual. Barcelona: Planeta Agostini.
- $\quad$-----(2004). Geopolítica del imperialismo contemporáneo. En W. Dierckxsens, \& C. Tablada, Guerra global, Resistencia Mundial y Alternativas. (págs. 37-58). Buenos Aires: CLACSO.

- Briceño Ruíz, J., Quintero Rizzuto, M. L., \& Ruíz de Benítez, D. (2013). El pensamiento estructuralista de la CEPAL sobre el desarrollo y la integración 
latinoamericana: reflexiones sobre su vigencia actual. Aportes para la integración latinoamericana, (28), 1-33.

- Cardoso, F. H., \& Faletto, E. (1977). Dependencia y desarrollo en América Latina. Buenos Aires: Siglo XXI.

- Corátolo, L. (2011). El aporte de Samir Amin al análisis del sistema mundial capitalista. Mendoza: Universidad Nacional de Cuyo.

- Díaz Colorado, F. (2012). La justicia desde las víctimas. Revista Misión Jurídica, (5): 267 - 275. DOI: https://doi. org/10.25058/1794600X.57

- Díez, M. A. (2013). El debate entre "estructuralismo" y "teoría de la dependencia" desde la Revista Desarrollo Económico. Opción: Revista de Ciencias Humanas y Sociales, (70), 9-30.

- Hardt, M., \& Negri, A. (2002). Imperio. Barcelona: Paidós.

- Lilloy, J. F. (2015). La Escuela Estructuralista Latinoamericana. Mendoza: Universidad Nacional de Cuyo.

- Linz, J. J. (1987). La quiebra de las democracias. Madrid: Alianza Editorial.

- Prebisch, R. (1963). El desarrollo económico de la América Latina y algunos de sus principales problemas. CEPAL.

- Sachs, J. (2015). La Era del Desarrollo
Sostenible. (R. Vilà, Trad.) Barcelona: Deusto.

- Santos, B. d. (2002). Producir para vivir. Los caminos de la producción no capitalista. Brasil: Civilizaçao Brasileira.

- -----.(2002). Hacia una concepción multicultural de los Derechos Humanos. El Otro Derecho, (28), 60-83.

- ----.(2006). La Sociología de las Ausencias y la Sociología de las Emergencias: para una ecología de saberes. En B. d. Santos, Renovar la teoría crítica y reinventar la emancipación social (encuentros en Buenos Aires) (págs. 13-41). Buenos Aires: CLACSO.

- -----.(2009). Sociología jurídica crítica. Para un nuevo sentido común en el derecho. Madrid: Trotta.

- ----.(2010). Descolonizar el saber, reiventar el poder. Montevideo: Trilce.

- ----.(2014). Derechos humanos, democracia y desarrollo. (C. F. Setién, Trad.) Bogotá: Dejusticia.

- -----.(2014). Si Dios fuese un activista de los derechos humanos. (C. M. Ramírez, Trad.) Madrid: Trotta.

- Santos, T. D. (2002). La teoría de la dependencia. Balances y Perspectivas. Barcelona: Plaza y Janés. 